\title{
GOVERNANÇA E CONTROLADORIA NO SETOR PÚBLICO: UMA ANÁLISE DO GOVERNO E DA CONTROLADORIA-GERAL DO ESTADO DE MINAS GERAIS
}

GOVERNANCE AND CONTROLLERSHIP IN THE PUBLIC SECTOR: AN ANALYSIS OF THE GOVERNMENT AND THE GENERAL-CONTROLLERSHIP OF THE MINAS GERAIS STATE

Diego Messias

Universidade Estadual do Oeste do Paraná, PR, Brasil E-mail: diegomessias.1986@gmail.com

Silvana Anita Walter

Universidade Estadual do Oeste do Paraná, PR, Brasil E-mail: silvanaanita.walter@gmail.com

Recebido em: 05.09.2018 - Aceito em: 18.01.2019

DOI: http://dx.doi.org/10.5902/2526629234635

\section{RESUMO}

Assim como na iniciativa privada, a governança e seus instrumentos são igualmente aplicáveis às instituições da administração pública, visando relacionar os objetivos políticos de forma eficiente e eficaz, além de proporcionar informações transparentes e fidedignas acerca de seus atos. Nesse sentido, o presente estudo objetivou identificar se as informações divulgadas nos relatórios do Governo e da Controladoria-Geral do Estado de Minas Gerais atendem às recomendações de governança estabelecidas no Estudo $n^{\circ} 13$ da Federação Internacional dos Contadores (IFAC). Realizaram-se pesquisa bibliográfica e posterior levantamento documental dos relatórios e demais informações disponibilizadas no portal eletrônico do ente governamental quanto à prestação de contas para a sociedade. A seguir, analisou-se o conteúdo dos documentos selecionados, conforme os preceitos de Bardin (2004), de forma a identificar sua estrutura e conteúdo para comparação com as diretrizes da IFAC. Verificou-se que o governo mineiro atende parcialmente às recomendações quanto à dimensão dos relatórios externos, apresentando as maiores divergências no relatório anual de prestação de contas.

PALAVRAS-CHAVE: Governança; Controladoria; Setor Público. 


\section{ABSTRACT}

Just as in the private sector, governance and yours instruments are also applicable to institutions of public administration, aiming to relate policy objectives efficiently and effectively, and provide transparent and reliable information about their actions. In that sense, this study aimed at identifying if the information published in the government and controllership reports of the Minas Gerais State obeys the governance recommendations stablished on the 13th IFAC study. The methodology adopted was constituted by bibliographical research, then a documental survey about the reports and other electronic information available on the sites of the State Government about account statement for the community. Additionally it was analyzed the content in the chosen documents, according Bardin (2004), to identify its structure and composition to compare with IFAC standards. It was found that Minas Gerais Government obeys partially the recommendations for the external reports, presenting the biggest divergences in the account statement annual report.

KEYWORDS: Governance; Controllership; Public Sector.

\section{INTRODUÇÃO}

No contexto social atual, a administração pública tem como função a gestão dos recursos financeiros estatais, objetivando o atendimento das necessidades da população por meio do oferecimento de serviços públicos que sejam de qualidade e que atendam a todos. Essa gestão se dá por meio do Poder Executivo, que é dirigido pelo presidente da República na esfera federal, pelos governadores em nível estadual e pelos prefeitos em nível municipal. De forma harmônica e independente entre si, atuam, além do Poder Executivo, o Poder Legislativo, na elaboração do regramento jurídico do Estado, e o Poder Judiciário, na solução de conflitos (Barroso, 2015).

Essa relação entre os cidadãos e os governantes gestores sociais pode ser analisada sob a luz da teoria da agência, pois fica evidenciada a existência da figura do agenciamento quando da análise dos contratos firmados, mesmo que de forma tácita, entre as partes. Outro fator que confirma a existência da relação e dos conflitos de agência entre a administração pública e a população é a observância de três condições básicas citadas por Slomski (2005), quais sejam: (i) possibilidade de comportamentos diversos pelo gestor público (agente); (ii) impacto das ações do agente no bem-estar de ambas as partes; e (iii) dificuldade de observação e acompanhamento de todas as ações do gestor pelo cidadão (principal).

Uma tendência nos últimos anos, trazida pela corrente da Nova Gestão Pú- 
blica (New Public Management), conforme citado por Mello (2006), é a adaptação de práticas, modelos e ferramentas gerenciais, normalmente utilizados apenas na iniciativa privada, nas atividades da gestão governamental, buscando maior eficiência, efetividade e economicidade para a administração. Essas práticas, que criam uma administração pública gerencial, podem contribuir para a redução dos conflitos de agência. Uma dessas ferramentas adaptadas no setor público é a governança corporativa.

A governança corporativa desenvolveu-se nos Estados Unidos, objetivando dar maior proteção aos proprietários, por meio da recuperação da transparência, da responsabilização e do monitoramento das ações dos gestores das organizações (Cavalcante \& De Luca, 2013). É balizada por recomendações de boas práticas, além de princípios aglomerados em dimensões, como, por exemplo, o controle (IFAC, 2001). Nesse prisma, a controladoria caracteriza-se como uma ferramenta necessária ao sistema de governança.

A controladoria pode contribuir para a gestão organizacional por meio de instrumentos gerenciais e de relevantes informações disponibilizadas em seus relatórios, que articulam o planejamento com o processo decisório (Durigon \& Diehl, 2013). No setor público, que tem algumas características mais complexas que a iniciativa privada, a controladoria pode atuar na identificação e classificação de problemas gerenciais, fornecendo ao gestor informações relevantes para a tomada de decisão.

$\mathrm{Na}$ atualidade, diversas entidades governamentais implantaram unidades de controladoria em sua estrutura organizacional. Em âmbito federal, foi criada, em 2003, a Controladoria-Geral da União (CGU) que, além das atividades de controle interno, atua no sistema de correição do funcionalismo, na transparência e na ouvidoria do governo federal. Governos estaduais, incentivados pelo trabalho realizado pela CGU, iniciaram o desenvolvimento de estudos acerca da implementação de sistemas de controle em sua gestão e alguns entes federativos implantaram controladorias estaduais.

Em 2001, foram instituídos, pelo Comitê do Setor Público da Federação Internacional dos Contadores (PSC/IFAC), princípios, diretrizes e recomendações de governança e controladoria a serem seguidos pelas entidades governamentais. A Federação Internacional dos Contadores (IFAC) segrega as recomendações em quatro dimensões, a saber: padrões de comportamento, processos e estrutura organizacional, controle, e relatórios externos. Entre os princípios elencados pela IFAC, três se destacam dos demais, quais sejam: transparência, integridade e accountability. 
Nos últimos anos, estudos vêm sendo realizados acerca da adoção das diretrizes da IFAC por entes governamentais internacionais e nacionais (Edwards, 2002; Mello \& Slomski, 2010; Santana Jr., Libonati, Vasconcelos, \& Slomski, 2009; Loureiro, Abrucio, Olivieri, \& Teixeira, 2012; Cavalcante \& De Luca, 2013; Cavalcante, Peter, Meneses, \& Machado, 2012). Nesse contexto, alicerçado na teoria da agência e nas boas práticas de governança e controladoria, este estudo objetiva responder à seguinte questão de pesquisa: quais das recomendações sugeridas pela IFAC, quanto à dimensão dos relatórios externos, são atendidas pelo Governo e pela Controladoria-Geral do Estado de Minas Gerais (CGE/ MG) na divulgação de seus relatórios? Almejando responder à questão de pesquisa, este estudo tem como objetivo verificar se as informações disponibilizadas pelo governo e pela CGE/MG em seus relatórios atendem às recomendações da IFAC quanto à dimensão dos relatórios externos.

O presente estudo está estruturado da seguinte maneira. A primeira seção conceitua e contextualiza a governança corporativa e sua adaptação na administração pública, bem como a controladoria em entidades governamentais. Na sequência, é apresentada a metodologia de coleta e análise dos dados utilizada no desenvolvimento do trabalho. Posteriormente, são analisados os dados coletados nos portais eletrônicos do governo e da Controladoria de Minas Gerais. Por fim, são apresentadas as conclusões a partir dos resultados encontrados.

\section{REFERENCIAL TEÓRICO}

\subsection{Governança corporativa}

A governança corporativa tem suas bases arraigadas na teoria da agência, por buscar a redução dos conflitos resultantes do agenciamento a terceiros da administração e da gestão das organizações. Jensen e Meckling (1976) definem agenciamento, ou relação de agência, como um contrato sob o qual uma ou mais pessoas - denominadas principais - empregam uma outra pessoa - agente - para executar serviços em seu nome, que impliquem na delegação de algum poder de decisão ao agente. Nesse sentido, a teoria da agência busca explicar as relações entre os membros de uma organização, partindo do pressuposto de que ambas as partes são motivadas, de forma predominante, pelos seus próprios interesses (Nossa, Kassai, \& Kassai, 2000).

Em um contexto de ampliação, expansão e diversificação das organizações, o qual acarreta no distanciamento entre o proprietário e a gestão, os conflitos de agência desenvolvem-se com maior frequência e complexidade (Nossa, Kassai, \& Kassai, 
2000). Nesse cenário de complexos relacionamentos, pode atuar a governança corporativa, buscando mitigar e reduzir embates de agenciamento organizacionais, entre os quais se pode citar a assimetria informacional (Cavalcante \& De Luca, 2013).

Para Hart (1995), questões de governança corporativa surgem em uma organização quando duas condições estão presentes. Quanto à primeira, há um problema de agência ou conflito de interesses envolvendo membros da organização (proprietários, gestores, trabalhadores ou consumidores). Em segundo lugar, os custos de transação são tais que este conflito de agência não pode ser tratado e controlado apenas por meio de um contrato, exigindo instrumentos mais efetivos de gerenciamento (Turnbull, 1997).

O Instituto Brasileiro de Governança Corporativa - IBGC (2009) define governança corporativa como um sistema pelo qual as organizações são dirigidas, monitoradas e incentivadas, envolvendo os relacionamentos entre proprietários, conselho de administração, diretoria e órgãos de controle. É uma sistemática pela qual as corporações são dirigidas e controladas, sob os princípios da transparência (openness), integridade (integrity) e responsabilização (accountability) (IFAC, 2001).

Na concepção da Organização para a Cooperação e Desenvolvimento Econômico - OCDE (2004), a governança molda a estrutura e a política organizacional, o que contribui para a saúde e estabilidade da economia. Boas práticas de governança convertem princípios em recomendações objetivas, alinhando interesses com a finalidade de preservar e otimizar o valor da organização, facilitando seu acesso a recursos e contribuindo para sua longevidade (IBGC, 2009).

Diante do exposto, fica evidente a contribuição das atividades de governança corporativa para as organizações, na otimização de seus meios e recursos e no alcance de melhores resultados. Nesse sentido, a gestão das entidades governamentais também pode (ou deve) se apropriar de tais técnicas e procedimentos, no intuito de oferecer melhores serviços à sociedade, e atingir, dessa forma, seus objetivos.

\subsection{Governança no setor público}

Na concepção de Turnbull (1997), a governança corporativa é aplicável a todos os tipos de instituições. Para sua implementação no âmbito da gestão pública, os procedimentos e princípios de governança corporativa da iniciativa privada necessitam ser adaptados de forma a se alinharem com as características próprias e fundamentais da atividade governamental. Isso porque as entidades do setor público devem satisfazer uma gama de complexos objetivos sociais, o que submete a administração pública a situações diferenciadas quanto à prestação de contas à sociedade (IFAC, 2001). 
A governança no setor público é uma forma de proteção à relação existente entre a administração, o controle e a supervisão, feita pela organização governamental, pela situação organizacional e pelas autoridades do governo, visando relacionar os objetivos políticos de forma eficiente e eficaz, além de proporcionar informações transparentes e fidedignas acerca de seus atos (Timmers, 2000 apud Mello, 2006; Turnbull, 1997).

Mello (2006) defende que a governança no setor público trata da gestão dos agenciamentos governamentais por meio dos princípios da governança corporativa do setor privado, que são totalmente aplicáveis ao poder geral do Estado. Ainda segundo o autor, as entidades do setor público devem comprometer-se em assegurar a integridade de seus atos e agir de forma a evitar comportamento não ético de seus agentes e gestores, incentivando a condução da gestão de forma transparente e responsável. Além disso, devem buscar meios para monitorar os papéis e responsabilidades de seus administradores (Edwards, 2002).

Nesse sentido, Magalhães e Coelho (2018) destacam que, nas últimas décadas, instaurou-se um processo endêmico de reforma do setor público, por meio do qual há uma transição da administração pública tradicional para uma gestão alinhada ao mundo dos negócios - cenário esse já contextualizado por Harrison (1998) há duas décadas. Esse processo de gerencialismo pressupõe que existe um conjunto padronizado de práticas do setor privado adequadas ao setor público e que tais práticas constituem uma abordagem com eficiência superior à tradicional (Mello, 2006).

\subsection{Diretrizes e princípios do PSC/IFAC}

O Public Sector Committee (PSC) é o comitê, vinculado à IFAC, responsável pelo desenvolvimento de estudos, diretrizes e normas em nível global, acerca da contabilidade e auditoria para as entidades governamentais.

Embasado em estudos ingleses anteriores, o PSC/IFAC desenvolveu, em 2001, o Estudo $n^{\circ} 13$, objetivando proporcionar melhorias para a governança e a prestação de contas governamental. O estudo traz princípios, diretrizes e recomendações para a adaptação da governança corporativa ao setor público, de acordo com suas características específicas.

Entre as características, pode-se citar a existência de diversas e simultâneas relações de agência (sociedade-gestor, gestor-gestor, gestor-justiça, fornecedor-gestor), os inúmeros stakeholders (cada um com seus legítimos, porém difusos, interesses), a forma de designação dos gestores (eleitos pelo povo ou nomeados politicamente), entre outras.

Nesse contexto, o PSC/IFAC identificou, entre outros, três princípios como fundamentais: transparência, integridade e responsabilização. 
Tabela 1 - Princípios de governança no setor público, segundo o PSC/IFAC

\begin{tabular}{|c|l|}
\hline Princípio & \multicolumn{1}{c|}{ Descrição } \\
\hline $\begin{array}{c}\text { Openness } \\
\text { (Transparência) }\end{array}$ & $\begin{array}{l}\text { Trata-se de o ente estar acessível para consultas por parte dos } \\
\text { interessados e fornecer informações claras, precisas e objetivas. } \\
\text { A transparência é necessária para dar confiança aos stakeholders } \\
\text { quanto às ações e decisões das entidades e dos gestores. }\end{array}$ \\
\hline $\begin{array}{c}\text { Integrity } \\
\text { (Integridade) }\end{array}$ & $\begin{array}{l}\text { Baseia-se em honestidade, objetividade e elevados padrões } \\
\text { de decência na administração dos fundos e recursos públicos. } \\
\text { Reflete tanto no processo decisório quanto na qualidade dos } \\
\text { relatórios financeiros e de desempenho. }\end{array}$ \\
\hline $\begin{array}{c}\text { Accountability } \\
\text { (Responsabilização) }\end{array}$ & $\begin{array}{l}\text { Trata-se da responsabilização dos indivíduos detentores do poder } \\
\text { de tomada de decisão quanto aos resultados de sua gestão. De } \\
\text { forma sucinta, é a obrigação de responder por atribuições que lhe } \\
\text { foram conferidas. }\end{array}$ \\
\hline
\end{tabular}

Fonte: Adaptada de IFAC (2001).

Percebe-se que os três princípios basilares da governança do setor público, na concepção do PSC/IFAC, são voltados à recuperação e manutenção da confiança da sociedade para com as entidades governamentais, fator necessário e indispensável ao funcionamento do Estado (Cavalcante \& De Luca, 2013).

Os princípios são relevantes para entidades do setor público da mesma forma como o são para entidades do setor privado. Aplicam-se igualmente a todas as entidades governamentais, independentemente de os gestores (agentes) serem eleitos pelo povo ou nomeados politicamente (Harrison, 1998; Mello, 2006). Ademais, refletem em cada uma das quatro dimensões e recomendações estabelecidas pelo PSC/IFAC, a saber: 
Tabela 2 - Dimensões e recomendações da governança no setor público segundo o PSC/IFAC

\begin{tabular}{|c|c|c|}
\hline Dimensão & Descrição & Recomendações \\
\hline $\begin{array}{l}\text { Standards of Beha- } \\
\text { vior (Padrões de } \\
\text { Comportamento) }\end{array}$ & $\begin{array}{l}\text { Esta dimensão aborda a forma } \\
\text { como a alta gestão da orga- } \\
\text { nização exerce sua liderança } \\
\text { na determinação dos valores, } \\
\text { padrões e cultura quanto ao } \\
\text { comportamento de seus ges- } \\
\text { tores e colaboradores. }\end{array}$ & $\begin{array}{l}\text { Liderança } \\
\text { Códigos de conduta } \\
\text { Probidade e propriedade } \\
\text { Objetividade, integridade e ho- } \\
\text { nestidade } \\
\text { Relacionamento }\end{array}$ \\
\hline $\begin{array}{l}\text { Organizacional } \\
\text { Structures and Pro- } \\
\text { cesses (Processos e } \\
\text { Estrutura Organiza- } \\
\text { cional) }\end{array}$ & $\begin{array}{l}\text { Esta dimensão aborda a for- } \\
\text { ma como os membros da alta } \\
\text { gestão das entidades são no- } \\
\text { meados, eleitos ou indicados, } \\
\text { como suas responsabilidades } \\
\text { são definidas e como eles são } \\
\text { responsabilizados pelos seus } \\
\text { atos. }\end{array}$ & $\begin{array}{l}\text { Responsabilidade estatutária } \\
\text { Responsabilidade em prestar } \\
\text { contas } \\
\text { Comunicação entre partes inte- } \\
\text { ressadas } \\
\text { Papéis e responsabilidade } \\
\text { Equilíbrio de poder e autoridade } \\
\text { Grupo de governo } \\
\text { Presidente } \\
\text { Membros não executivos do go- } \\
\text { verno } \\
\text { Administração executiva } \\
\text { Política de remuneração }\end{array}$ \\
\hline Control (Controle) & $\begin{array}{l}\text { Esta dimensão aborda a for- } \\
\text { ma como se dá o estabeleci- } \\
\text { mento dos controles pela alta } \\
\text { administração para o alcance } \\
\text { dos objetivos da entidade, a } \\
\text { eficácia e a eficiência das ope- } \\
\text { rações, a confiabilidade da in- } \\
\text { formação e dos relatórios e a } \\
\text { conformidade dos atos com as } \\
\text { leis e regulamentos aplicáveis. }\end{array}$ & $\begin{array}{l}\text { Gestão de risco } \\
\text { Auditoria interna } \\
\text { Comitês de auditoria } \\
\text { Controle interno } \\
\text { Orçamento } \\
\text { Administração financeira } \\
\text { Treinamento de pessoal }\end{array}$ \\
\hline $\begin{array}{l}\text { External Reporting } \\
\text { (Relatórios Externos) }\end{array}$ & $\begin{array}{l}\text { Esta dimensão aborda como } \\
\text { a alta administração da orga- } \\
\text { nização demonstra seu de- } \\
\text { sempenho na utilização dos } \\
\text { recursos públicos, bem como } \\
\text { sua responsabilização pelos } \\
\text { resultados obtidos. }\end{array}$ & $\begin{array}{l}\text { Relatórios anuais } \\
\text { Uso de normas contábeis ade- } \\
\text { quadas } \\
\text { Medidas de desempenho } \\
\text { Auditoria externa }\end{array}$ \\
\hline
\end{tabular}

Fonte: Adaptada de IFAC (2001).

As quatro dimensões consideradas pelo PSC/IFAC abrangem toda a gestão da organização e, a partir delas, foram estabelecidas recomendações de governança e boas práticas a serem seguidas pelos entes estatais, conforme se observa na Tabela 2. 


\subsection{Dimensão dos relatórios externos}

Para este estudo, destaca-se, entre as demais, a dimensão dos Relatórios Externos, que fornece diretrizes para atendimento dos princípios da accountability e da transparência, contribuindo para a redução da assimetria informacional e, consequentemente, dos conflitos incidentes nas várias relações de agenciamento existentes na atividade governamental (Mello, 2006).

A dimensão traz quatro recomendações, detalhadas na Tabela 3.

Tabela 3 - Dimensão dos relatórios externos segundo o PSC/IFAC

\begin{tabular}{|l|l|}
\hline Recomendação & Descrição \\
\hline Relatório anual & $\begin{array}{l}\text { As entidades devem publicar anualmente e tempestivamente } \\
\text { relatório de prestação de contas (incluindo as demonstrações } \\
\text { contábeis), o qual deve demonstrar, de forma equilibrada e ob- } \\
\text { jetiva, as atividades realizadas em comparação com as previ- } \\
\text { sões, a posição financeira e as perspectivas de desempenho. }\end{array}$ \\
\hline $\begin{array}{l}\text { Uso de normas contá- } \\
\text { beis adequadas }\end{array}$ & $\begin{array}{l}\text { As entidades devem utilizá-las para a elaboração de suas de- } \\
\text { monstrações financeiras, de modo que estas sejam preparadas } \\
\text { de acordo com os Padrões Internacionais de Contabilidade Públi- } \\
\text { ca (International Public Accounting Standards - IPSAS) ou outras } \\
\text { normas contábeis de referências, além da legislação em vigor. }\end{array}$ \\
\hline $\begin{array}{l}\text { Medidas de desempe- } \\
\text { nho }\end{array}$ & $\begin{array}{l}\text { As entidades devem demonstrar, por meio de indicadores de de- } \\
\text { sempenho, bem como de sua metodologia de cálculo, que os } \\
\text { recursos públicos foram aplicados de forma eficiente e eficaz. }\end{array}$ \\
\hline Auditoria externa & $\begin{array}{l}\text { As entidades devem manter relacionamento profissional e ob- } \\
\text { jetivo com seus auditores externos. }\end{array}$ \\
\hline
\end{tabular}

Fonte: Adaptada de IFAC (2001).

As recomendações da dimensão dos relatórios externos almejam a redução da assimetria informacional, por meio da divulgação tempestiva de informações aos diversos stakeholders. Ademais, induzem o administrador público a realizar apenas procedimentos de acordo com as normas e apresentar evidências do desempenho de sua gestão, o que proporciona aos usuários uma informação mais relevante em relação aos relatórios contábeis tradicionais (IFAC, 2001; Mello, 2006; Cavalcante \& De Luca, 2013).

Além de disponibilizar informações à sociedade, é necessário que estas estejam revestidas de atributos que concedam confiabilidade. Como exemplo, Fontes Filho e Alves (2018) destacam um achado relevante detectado em comparativo entre os governos brasileiro e português. Em Portugal, uma unidade técnica interna e independente procede à análise dos relatos do governo e elabora, ela própria, um relatório anual sobre o cumprimento das práticas de boa gestão. 
Nesse contexto de amplas recomendações de boas práticas, verifica-se a complexidade inerente às atividades de governança. Para que a gestão possa atender de forma plena às recomendações quanto à divulgação de relatórios externos, é necessário que o controle esteja presente em suas operações cotidianas. O controle, como uma das dimensões tratadas pelos PSC/IFAC, é peça-chave para o atendimento das demais boas práticas de governança.

\subsection{Controladoria como instrumento de governança}

Para Cavalcante e De Luca (2013), a governança no setor público deve ser norteada por controles, que reduzem deficiências da gestão e, consequentemente, mitigam os conflitos de agência. Ainda segundo os autores, uma organização com controles adequados tende a ampliar sua transparência dos atos de gestão perante as partes interessadas, assegurando que conflitos de interesse não interfiram na capacidade organizacional de obtenção de resultados econômicos. As ações de controle, essência da controladoria, são indispensáveis às atividades de gestão das organizações (IFAC, 2001).

Controladoria pode ser compreendida como a busca pelo alcance do ótimo em qualquer ente, seja ele público ou privado; é o "algo mais" procurado pelo conjunto de elementos que compõem a máquina de qualquer entidade (Slomski, 2005). Pode ser conceituada, ainda, como um conjunto de atividades que contribui para o fortalecimento e desenvolvimento da organização, através de relatórios e outros instrumentos gerenciais que auxiliam os administradores no processo decisório (Durigon \& Diehl, 2013).

A controladoria tem um amplo escopo de trabalho, atuando desde o planejamento estratégico, passando pelo processo de execução e chegando até o processo de avaliação dos resultados. Quando inserida no contexto da gestão pública, também possui papel econômico ao contribuir para a melhoria dos resultados, buscando otimizar a utilização dos recursos em benefício da sociedade (Oliveira, 2010).

$\mathrm{Na}$ gestão governamental, a controladoria tem como principal objeto os recursos públicos que, para Slomski (2005), sustentado por um tripé composto de recursos humanos, recursos financeiros e recursos físicos, devem ser considerados pelo controller sempre de maneira conjunta, nunca dissociada, na avaliação da gestão da coisa pública. Ou seja, a controladoria, quando existente na atividade pública, proporciona melhorias significativas na gestão. 


\subsection{Controladoria-Geral do Estado de Minas Gerais}

A implementação de parte das atividades de governança no setor público se dá, via de regra, por meio da institucionalização de unidades ou órgãos de controladoria. No Brasil, em nível nacional, há a Controladoria-Geral da União (CGU), que atua em atividades de controle, transparência, correição e ouvidoria, e em alguns estados há controladorias locais, nem sempre desenvolvendo atividades com o mesmo escopo que a CGU.

No estado de Minas Gerais, foi criada, por meio da Lei Delegada ${ }^{\circ} 180$, de 20 de janeiro de 2011, a Controladoria-Geral do Estado de Minas Gerais (CGE/ $M G)$, para atuar na prevenção e combate à corrupção na gestão estadual, garantir a defesa do patrimônio público, promover a transparência e a participação social e contribuir para a melhoria da qualidade dos serviços públicos (CGE/MG, 2015).

A CGE/MG é órgão central do sistema de controle interno do poder executivo mineiro e tem por finalidade assistir o governador do estado no desempenho de suas atribuições quanto à defesa do patrimônio público, ao controle interno, à auditoria pública, à correição, à prevenção e combate à corrupção e ao incremento da transparência da gestão no âmbito da administração pública estadual (CGE/MG, 2015).

Para o alcance de seus objetivos, a CGE/MG atua em três frentes de trabaIho ou macrofunções, a saber:

I. auditoria: acompanhamento da aplicação dos recursos públicos estaduais;

II. correição: apuração da conduta de agentes públicos do Estado e aplicação de eventuais penalidades; e

III. transparência: gestão de políticas de transparência e fomento à participação da sociedade na fiscalização dos gastos públicos (CGE/MG, 2015).

Verifica-se que a CGE/MG tem um vasto campo de atuação na administração pública mineira ao abranger, de forma similar à CGU, atividades de controle, auditoria e correição. As atividades desenvolvidas pela controladoria não se restringem às recomendações do PSC/IFAC quanto à dimensão do controle, pois abrangendo também parte das recomendações e atividades contidas na dimensão dos relatórios externos, objeto deste estudo.

\section{MÉTODO DE PESQUISA}

Em virtude de seu objetivo, o presente estudo classifica-se como exploratório, que, na visão de Hair Jr., Babin, Money e Samouel (2005), é útil ao pesquisador que dispõe de limitadas informações quanto ao tema, por ser voltado à descoberta e por não ter a intenção de testar hipóteses. Nesse sentido, foram adotados procedimentos de coleta de dados de forma bibliográfica e documental, 
com abordagem qualitativa dos dados, que configura um processo de interpretação de dados feito com o objetivo de descobrir conceitos e relações em um esquema explanatório teórico (Strauss \& Corbin, 2008).

A exploração se deu por meio da pesquisa bibliográfica, realizada em bases de dados de periódicos nacionais e internacionais, além de sites, dissertações e livros, onde se buscaram conhecimentos em temáticas como a governança corporativa, a governança no setor público, a controladoria e o Estudo ${ }^{\circ} 13$ do PSC/IFAC.

A definição da controladoria mineira (e, consequentemente, do governo estadual mineiro) como objeto deste estudo se deu pelo motivo de o escopo dos trabalhos do órgão não se limitar às atividades (e à dimensão) de controle, contemplando parte das recomendações e atividades contidas na dimensão dos relatórios externos do PSC/IFAC. Esse fator foi decisivo, tendo em vista que outras controladorias estaduais têm escopo reduzido.

Optou-se por abordar unicamente a dimensão dos relatórios externos, uma vez que os relatórios contemplam extenso material para análise, fonte de uma gama volumosa de informações a serem validadas.

A pesquisa documental restou caracterizada pela coleta e análise de relatórios e informações divulgadas pela gestão do executivo e pela controladoria mineira em seus sites institucionais. Foram selecionados documentos e informações relacionadas à prestação de contas do governador, execução orçamentária e financeira, auditoria, avaliação de programas de governo, indicadores, entre outros, referentes aos exercícios de 2011 a 2015. Os documentos analisados são os seguintes:

a. relatório contábil (exercícios de 2010 a 2014);

b. mensagem à Assembleia Legislativa (exercícios de 2010 a 2014);

c. acordo de resultados entre governo e Controladoria de MG (2013 e 2014);

d. portal da transparência (informações diversas do exercício corrente);

e. painel de indicadores do governo (www.mapaderesultados.mg.gov.br);

f. informativo CGE ativa (edições de julho e novembro de 2015).

Os documentos selecionados passaram pelo processo de análise de conteúdo, que, na concepção de Bardin (2004), não se trata de um instrumento, mas de um conjunto de técnicas de análise dos formatos diversos de comunicação. O método foi executado nas três etapas previstas pela autora, quais sejam: (i) pré-análise, (ii) exploração do material e (iii) tratamento dos resultados obtidos e interpretação.

$\mathrm{Na}$ análise prévia, foi realizada a escolha, e leitura superficial, dos documentos e informações no portal eletrônico da CGE/MG que poderiam subsidiar o estudo pretendido. 
A segunda etapa consistiu na leitura pormenorizada dos documentos, de forma a capturar e classificar suas características quanto à forma de apresentação, ao tipo de informação e ao escopo. Esse procedimento resultou em um mapeamento das características das informações.

Ainda na segunda etapa (exploração do material), foi realizada, em instrumento próprio, a comparação das características dos documentos divulgados pela CGE/ MG com as recomendações quanto aos relatórios externos constantes no Estudo $\mathrm{n}^{\circ}$ 13 do PSC/IFAC. O instrumento classifica os itens analisados em quatro categorias quanto ao atendimento das recomendações: sim, parcial, não e não aplicável.

$\mathrm{Na}$ última e terceira etapa, procedeu-se à interpretação dos resultados encontrados no processo de comparação, gerando as inferências que estão dispostas na seção seguinte e nas conclusões.

\section{APRESENTAÇÃO E DISCUSSÃO DOS RESULTADOS}

Os relatórios e informações coletados para este estudo estão dispostos em diversas páginas do portal do governo do estado (www.mg.gov.br) e da Controladoria-Geral (controladoriageral.mg.gov.br). Estão alocados nos endereços das diversas unidades que contribuem para a produção e divulgação da informação, como a Secretaria de Planejamento, Orçamento e Gestão (Seplag), Secretaria da Fazenda (Sefaz), Portal da Transparência e as subcontroladorias componentes da CGE/MG (auditoria, correição e transparência).

A análise dos documentos selecionados foi focada em informações vinculadas à dimensão da divulgação externa, como demonstrações contábeis, prestação de contas da gestão, práticas de governança, indicadores de desempenho, apresentação de objetivos e responsabilidades, entre outras.

\subsection{Relatório contábil (2010 a 2014)}

O relatório contábil apresenta as declarações contábil-financeiras de cada exercício (balanços orçamentário, financeiro, patrimonial e de variações patrimoniais), notas explicativas acerca da execução orçamentária e financeira e evolução patrimonial. Apresenta, também, de forma sucinta, os instrumentos de planejamento institucional.

O relatório também demonstra a evolução da arrecadação e destinação dos recursos públicos, destacando as principais pastas do governo, como educação, saúde e segurança. São fornecidos, também, indicadores fiscais, estabelecidos pela Lei de Responsabilidade Fiscal (LRF), e constitucionais, quanto à saúde e educação.

Nos relatórios dos exercícios financeiros de 2010 a 2012, é apresentada a 
declaração de que as demonstrações contábil-financeiras foram elaboradas de acordo com a Lei $n^{\circ} 4.320 / 64$, norma que rege o direito financeiro em âmbito nacional. Já nos relatórios dos exercícios de 2013 e 2014, consta a declaração de atendimento às Normas Brasileiras de Contabilidade Aplicadas ao Setor Público (NBCASP), que são as equivalentes às normas internacionais (IPSAS).

O relatório referencia um decreto estadual que atribui responsabilidade dos dirigentes, ordenadores de despesas e contadores, quanto aos resultados de gestão apresentados.

\subsection{Mensagem à Assembleia Legislativa (2011 a 2015)}

O documento, enviado anualmente pelo governador ao Poder Legislativo para apreciação, contém a prestação de contas da gestão do Executivo referente ao exercício financeiro anterior. Traz informações acerca das metas físicas e financeiras, bem como um comparativo entre o estimado e o realizado. Além disso, faz um apanhado (exceto na mensagem do exercício de 2015) da conjuntura econômica nacional e mineira, apresentando indicadores econômicos acerca do desempenho das contas públicas.

São abordadas todas as pastas do governo (saúde, educação, segurança etc.), apresentando os principais resultados de suas atividades, bem como a execução de suas metas físicas e financeiras.

\subsection{Acordo de resultados entre governo e Controladoria de MG (2013 e 2014)}

O acordo, assinado entre o governador e a CGE, tem por objeto a pactuação de alcance dos resultados almejados no plano plurianual (PPAG), de acordo com as diretrizes estabelecidas no planejamento estratégico mineiro (PMDI). O acordo tem os seguintes objetivos: a) execução do caderno de gestão integrada e eficiente, composto pelas ações de melhoria institucional e ações intersetoriais; e b) execução dos indicadores de qualidade do gasto.

Ademais, apresenta a missão, a visão, os objetivos finalísticos (quanto ao estado e quanto à sociedade) e os objetivos de apoio (quanto a produtos internos e financeiros, aprendizagem e crescimento). Nos anexos, são divulgadas as metas de cada equipe e as sistemáticas de avaliação e acompanhamento do acordo. 


\subsection{Portal da transparência}

No portal, são disponibilizadas informações sobre receitas e despesas orçamentárias, dívida pública estadual, despesas com pessoal, repasses constitucionais aos municípios, cidadania fiscal. Também são apresentados os instrumentos de planejamento, além de informações fiscais, exigidas pela Lei de Responsabilidade Fiscal.

As informações são dispostas no portal de forma isolada, não possibilitando ao usuário a análise conjunta de dados. Segundo dados do informativo CGE Ativa de julho/2015, está em desenvolvimento um novo portal da transparência.

\subsection{Painel de indicadores do governo}

O mapa de resultados do governo mineiro constitui-se de um portal eletrônico que disponibiliza informações quanto ao perfil do estado, de suas regiões e de seus municípios no que se refere a educação, saúde, economia, segurança e infraestrutura. Além disso, traz uma série de indicadores de educação, saúde, segurança, além de um indicador financeiro (arrecadação de ICMS).

\subsection{Informativo CGE Ativa}

O CGE Ativa é um informativo periódico emitido pela controladoria mineira, direcionado para o público externo, contendo notícias sobre o orçamento, auditoria, transparência, correição, atividade disciplinar e outras relacionadas aos trabaIhos da corregedoria.

A Tabela 4 representa o instrumento de análise de conteúdo utilizado na pesquisa, com os resultados da comparação das informações disponibilizadas pelo governo e controladoria-geral mineira, com as recomendações constantes no Estudo $\mathrm{n}^{\circ} 13$ do PSC/IFAC. 
Tabela 4 - Instrumento de análise de conteúdo das informações do governo e da CGE/MG

\begin{tabular}{|c|c|c|c|c|}
\hline \multirow{2}{*}{$\begin{array}{c}\text { Recomendações } \\
\text { gerais }\end{array}$} & \multirow{2}{*}{ Recomendações detalhadas } & \multicolumn{3}{|c|}{ Atendimento } \\
\hline & & $S$ & $P$ & $N$ \\
\hline \multirow{7}{*}{ 1. Relatório anual } & $\begin{array}{l}1.1 \text { - Demonstrações financeiras publicadas/ } \\
\text { disponibilizadas tempestivamente }\end{array}$ & & & \\
\hline & $\begin{array}{l}1.2 \text { - Demonstrações financeiras auditadas e } \\
\text { relatórios dos auditores }\end{array}$ & & & \\
\hline & $\begin{array}{l}\text { 1.3 - Declaração de adoção ou não de práticas de } \\
\text { governança }\end{array}$ & & & \\
\hline & $\begin{array}{l}1.4 \text { - Declaração de efetivo cumprimento das } \\
\text { práticas de governança }\end{array}$ & & & \\
\hline & $\begin{array}{l}1.5 \text { - Declaração de objetivos com medidas de } \\
\text { desempenho }\end{array}$ & & & \\
\hline & $\begin{array}{l}1.6 \text { - Forma de nomeação e remuneração dos } \\
\text { gestores }\end{array}$ & & & \\
\hline & $\begin{array}{l}1.7 \text { - Declaração de responsabilidades (aprovação } \\
\text { de planos orçamentários e financeiros, estado dos } \\
\text { negócios, estrutura de controle, uso de políticas } \\
\text { contábeis apropriadas) }\end{array}$ & & & \\
\hline $\begin{array}{l}\text { 2. Uso de normas } \\
\text { contábeis } \\
\text { adequadas }\end{array}$ & $\begin{array}{l}2.1-\text { Declaração de elaboração das } \\
\text { demonstrações financeiras de acordo com as } \\
\text { Normas Internacionais de Contabilidade Aplicada } \\
\text { ao Setor Público (IPSAS) }\end{array}$ & & & \\
\hline \multirow{3}{*}{$\begin{array}{l}\text { 3. Medidas de } \\
\text { desempenho }\end{array}$} & $\begin{array}{l}3.1 \text { - Estabelecimento de medidas de desempenho } \\
\text { (economicidade, eficiência, efetividade e e } \\
\text { conveniência) }\end{array}$ & & & \\
\hline & $\begin{array}{l}3.2 \text { - Estabelecimento de medidas de desempenho } \\
\text { não monetárias }\end{array}$ & & & \\
\hline & $\begin{array}{l}3.3 \text { - Comparação dos indicadores com outros } \\
\text { exercícios, com outras entidades similares } \\
\text { (benchmarking) e entre estimado e realizado }\end{array}$ & & & \\
\hline $\begin{array}{l}\text { 4. Auditoria } \\
\text { externa }\end{array}$ & $\begin{array}{l}4.1 \text { - Manutenção de comitê de relacionamento } \\
\text { profissional com os auditores externos }\end{array}$ & & & \\
\hline
\end{tabular}

Legenda: S: Sim; P: Parcial; N: Não; NA: Não aplicável.

Fonte: Elaborada pelo autor.

Examinando o instrumento de análise de conteúdo, verificam-se as recomendações de governança adotadas pelo governo mineiro. Na sequência, analisa-se o atendimento de cada recomendação, quanto à dimensão dos relatórios externos.

\subsection{Relatório anual}

$\mathrm{Na}$ análise, foram considerados os seguintes documentos: relatórios contábeis e as mensagens encaminhadas pelo governador ao Legislativo.

Verifica-se, na análise, que as demonstrações contábeis do governo do estado foram tempestivamente divulgadas em seu portal (1.1). Todavia, o relatório 
não afirma que as demonstrações passaram por processo de auditoria interna (1.2). Também não foram localizados documentos da CGE/MG que confirmem a realização da auditoria.

Quanto à auditoria externa, que, no caso, é de responsabilidade do Poder Legislativo com auxílio do Tribunal de Contas do Estado (TCE), também não foi localizada nenhuma informação quanto a sua realização.

Não consta, nos documentos analisados, declaração de adoção de práticas de governança pelo ente estatal (1.3). Todavia, nos instrumentos de planejamento e na prestação de contas do executivo, a governança é citada na descrição de alguns programas de governo (exemplo: programa 158 - governança eletrônica). Também não há declaração de efetivo cumprimento das práticas de governança (1.4).

O ente governamental dispõe de termo de acordo de resultados firmado com a controladoria, que lista objetivos organizacionais, bem como suas medidas de desempenho. Nesse sentido, o item 1.5 resta como atendido. Em virtude de o processo de escolha do gestor estatal se dar por eleição, o item 1.6 não se aplica à análise. $O$ item 1.7 foi considerado como de atendimento parcial, tendo em vista que houve referência a apenas um dispositivo legal que discorre sobre algumas responsabilidades.

\subsection{Uso de normas contábeis adequadas}

Os documentos considerados na análise foram relatórios contábeis.

O governo mineiro atende à recomendação ao dispor que, nas notas explicativas de seus relatórios contábeis anuais, elabora suas demonstrações contábeis em conformidade com as Normas Brasileiras de Contabilidade, que correspondem à tradução das normas internacionais. Vale ressaltar que a declaração de atendimento às normas, além de recomendação do PSC/IFAC, é, também, uma exigência legal nacional.

\subsection{Medidas de desempenho}

$\mathrm{Na}$ análise, foram considerados os seguintes documentos: relatórios contábeis, mensagens encaminhadas pelo governador ao Legislativo, acordo de resultados e painel de indicadores.

O acordo de resultados, a mensagem enviada ao Legislativo e o painel de indicadores do governo apresentam algumas métricas de desempenho adotadas pelo governo (3.1 e 3.2), tanto de itens monetários (arrecadação e destinação, custo de programas), como não monetários (IDH, IDEB, mortalidade infantil). 
Os relatórios trazem comparativos de indicadores com exercícios anteriores e conta com manual de estruturação da metodologia de benchmarking. Entretanto, não foi encontrada informação que confirme a institucionalização da prática do benchmarking (3.3).

\subsection{Auditoria externa}

Não foram encontrados documentos que mencionassem a criação ou existência de comitê de relacionamento com a auditoria externa (4.1).

Diante do exposto acerca da comparação das informações apresentadas pelo governo e pela Controladoria-Geral do Estado de Minas Gerais em relação às recomendações de práticas de governança para entidades do setor público estabelecidas pelo PSC/IFAC, verifica-se que, dos 12 itens relacionados à dimensão dos relatórios externos, $50 \%$ são atendidos plenamente, 25\% não são atendidos e outros $16 \%$ são atendidos parcialmente.

\section{CONSIDERAÇÕES FINAIS}

Buscando estimar o nível de adoção de práticas de governança em entidades do setor público, este estudo objetivou verificar se as informações disponibilizadas pelo governo e pela Controladoria-Geral do Estado de Minas Gerais em seus relatórios atendem às recomendações da IFAC quanto à dimensão dos relatórios externos.

No desenvolvimento da pesquisa, verificou-se que a adoção de práticas de governança por entidades governamentais vem crescendo nos últimos anos, assim como de outras técnicas administrativas oriundas da iniciativa privada. Esse movimento de reforma da atividade estatal se dá em busca de eficiência, efetividade e economicidade aos serviços prestados à sociedade. De forma a orientar o processo de reforma e trazer melhorias para a gestão pública, o PSC/IFAC elaborou uma série de recomendações e princípios de governança a serem adotados pelos entes estatais.

Nesse sentido, após análise de conteúdo de diversos documentos divulgados e disponibilizados pelo executivo mineiro e sua controladoria em seu portal eletrônico, ficou demonstrado que o ente atende plenamente às recomendações quanto ao uso de normas contábeis adequadas e medidas de desempenho e parcialmente às recomendações quanto ao relatório anual. 
Essa constatação demonstra que os relatórios divulgados pelo governo mineiro necessitam de melhorias em alguns aspectos, como nas informações acerca da auditoria das demonstrações contábeis e das responsabilidades dos gestores. Outro aspecto relevante que o governo de Minas Gerais demonstrou não atender é justamente a temática deste estudo: a governança. Não são declaradas, de forma clara, a adoção de procedimentos de governança, bem como seus resultados. A análise de conteúdo também constatou que não é atendida a recomendação de manutenção de comitê de relacionamento com auditores externos.

Diante de todo o exposto, conclui-se que o governo e a Controladoria-Geral do Estado de Minas Gerais atendem de forma parcial às recomendações do PSC/ IFAC quanto à dimensão dos relatórios externos, em suas práticas de governança. Assim sendo, a questão de pesquisa considera-se respondida.

Entretanto, ressalta-se que os resultados obtidos são limitados, devido ao fato de a análise dos relatórios e informações se dar de forma superficial e de ser realizada de forma externa. Os resultados também se limitam ao ente estudado e não podem ser extrapolados para conclusões acerca de outros órgãos do setor público.

Em virtude dos resultados alcançados pelo estudo, recomenda-se que, em outras investigações, sejam analisados outros entes governamentais de forma conjunta, inclusive de outros poderes ou esferas.

\section{REFERÊNCIAS}

Bardin, L. (2004). Análise de conteúdo. Lisboa: Edições 70.

Barroso, L. R. (2015). Curso de direito constitucional contemporâneo: os conceitos fundamentais e a construção do novo modelo. São Paulo: Saraiva.

Cavalcante, M. C. N., \& De Luca, M. M. M. (2013). Controladoria como Instrumento de Governança no Setor Público. Revista de Educação e Pesquisa em Contabilidade (REPeC), 7(1), 73-90.

Cavalcante, M. C. N., Peter, M. D. G. A., Meneses, A. F. de, \& Machado, M. V. V. (2012). Controle como dimensão de governança pública: estudo nas controladorias federal e estaduais brasileiras. Anais do Congresso Brasileiro de Custos- $A B C$. Bento Gonçalves, 19.

Controladoria-Geral do Estado de Minas Gerais (2015). Objetivo operacional e competências legais da CGE/MG. Belo Horizonte. Recuperado de: http:// controladoriageral.mg.gov.br/sobre/competencias-legais

Durigon, A. R., \& Diehl, C. A. (2013). Controladoria no setor público: uma análise dos artigos publicados no Congresso USP de Controladoria e Contabilida- 
de-Período de 2001 a 2011. Contabilidade Vista \& Revista, 24(2), 91-109.

Edwards, M. (2002). Public sector governance - future issues for Australia. Australian Journal of Public Administration, 61(2), 51-61.

Fontes Filho, J. R., \& Alves, C. F. (2018). Mecanismos de controle na governança corporativa das empresas estatais: uma comparação Brasil e Portugal. Cadernos EBAPE. BR, 16(1), 1-13.

Hair Jr., J. F., Babin, B., Money, A. H., \& Samouel, P. (2005). Fundamentos de métodos de pesquisa em administração. Porto Alegre: Bookman.

Hart, O. (1995). Corporate governance: some theory and implications. Economic Journal, 105, 678-689.

Harrison, J. J. (1998). Corporate governance in the NHS - an assessment of boardroom practice. Corporate Governance: An International Review, 6(3), 140-150.

Instituto Brasileiro de Governança Corporativa (2009). Código das melhores práticas de governança corporativa (4. ed.). São Paulo: IBGC.

International Federation of Accountants. (2001). Governance in the public sector: $A$ governing body perspective. Recuperado de: https://www.iaasb.org/system/ files/publications/files/study-13-governance-in-th.pdf

ludícibus, S. de, Marion, J. C., \& Pereira, E. (2003). Dicionário de termos de contabilidade. São Paulo: Atlas.

Jensen, M. C., \& Meckling, W. H. (1976). Thory of the firm: managerial behavior, agency costs and ownership structure. Journal of Financial Economics, 3(4), 305-360.

Loureiro, M. R., Abrucio, F. L., Olivieri, C., \& Teixeira, M. A. C. (2012). Do controle interno ao controle social: a múltipla atuação da CGU na democracia brasileira. Cadernos Gestão Pública e Cidadania, 17(60), 54-67.

Magalhães, B. D., \& Coelho, F. D. S. (2018). Imbricações entre governança pública e governabilidade para a implementação da reforma administrativa: o caso da gestão para a cidadania em Minas Gerais (2011-2014). Gestão \& Planejamento, 10(1), 350-366.

Mello, G. R. (2006). Governança corporativa no setor público federal brasileiro (Dissertação de Mestrado, Faculdade de Economia, Administração e Contabilidade, Universidade de São Paulo, São Paulo). Recuperado de: http:// www.teses.usp.br/teses/disponiveis/12/12136/tde-28072006-093658/

Mello, G. R., \& Slomski, V. (2010). Índice de governança eletrônica dos estados brasileiros (2009): no âmbito do poder executivo. Journal of Information Sys- 
tems and Technology Management, 7(2), 375-408.

Nossa, V., Kassai, J. R., \& Kassai, S. (2000). A teoria do agenciamento e a contabilidade. Anais do Encontro Anual da Associação Nacional de Pós-Graduação em Administração, Florianópolis, SC, Brasil, 24.

Oliveira, A. B. S. (2010). Controladoria governamental: governança e controle econômico na implementação das políticas públicas. São Paulo: Atlas.

Organization for Economic Co-Operation and Development (2004). Principles of corporate governance. Recuperado de: http://www.oecd.org/daf/ca/Corporate-Governance-Principles-ENG.pdf

Santana Jr, J. J. B., Libonati, J. J., Vasconcelos, M. T. C., \& Slomski, V. (2009). Transparência fiscal eletrônica: uma análise dos níveis de transparência apresentados nos sites dos Poderes e Órgãos dos estados e do Distrito Federal do Brasil. Revista de Educação e Pesquisa em Contabilidade, 3(3), 62-84.

Slomski, V. (2005). Controladoria e governança na gestão pública. São Paulo: Atlas.

Strauss, A., \& Corbin, J. (2008). Pesquisa qualitativa: técnicas e procedimentos para o desenvolvimento de teoria fundamentada. Porto Alegre: Artmed.

Turnbull, S. (1997). Corporate Governance: its scope, concerns and theories. Corporate governance, 5(4), 180-205. 